\title{
The Influence of Different Retinal Subcircuits on the Nonlinearity of Ganglion Cell Behavior
}

\author{
Matthias H. Hennig, ${ }^{1}$ Klaus Funke, ${ }^{2}$ and Florentin Wörgötter ${ }^{1}$ \\ 1/nstitute for Neuronal Computational Intelligence and Technology, Department of Psychology, University of Stirling, \\ Stirling, FK9 4LA, United Kingdom, and IInstitut für Physiologie, Ruhr-Universität Bochum, D-44780 Bochum, Germany
}

\begin{abstract}
Y-type retinal ganglion cells show a pronounced, nonlinear, frequency-doubling behavior in response to modulated sinewave gratings. This is not observed in X-type cells. The source of this spatial nonlinear summation is still under debate. We have designed a realistic biophysical model of the cat retina to test the influence of different retinal cell classes and subcircuits on the linearity of ganglion cell responses. The intraretinal connectivity consists of the fundamental feedforward pathway via bipolar cells, lateral horizontal cell connectivity, and two amacrine circuits. The wiring diagram of $X$ - and $Y$-cells is identical apart from two aspects: (1) Y-cells have a wider receptive field and (2) they receive input from a nested amacrine circuit consisting of narrow- and wide-field amacrine cells. The model was tested with contrast-reversed gratings. First and
\end{abstract}

second harmonic response components were determined to estimate the degree of nonlinearity. By means of circuit dissection, we found that a high degree of the Y-cell nonlinear behavior arises from the spatial integration of temporal photoreceptor nonlinearities. Furthermore, we found a weaker and less uniform influence of the nested amacrine circuit. Different sources of nonlinearities interact in a multiplicative manner, and the influence of the amacrine circuit is $\sim 25 \%$ weaker than that of the photoreceptor. The model predicts that significant nonlinearities occur already at the level of horizontal cell responses. Pharmacological inactivation of the amacrine circuit is expected to exert a milder effect in reducing ganglion cell nonlinearity.

Key words: receptive field; rectification; ganglion cell; amacrine cell; cat retina; model
The mammalian retina encodes visual information in several different parallel channels (Roska and Werblin, 2001). An important functional classification is the distinction between linear and nonlinear responding ganglion cells (for review, see Kaplan and Benardete, 2001). Y-cells, which form the transient channel of the retinal output, exhibit nonlinear spatial summation. X-cells are essentially linear (Enroth-Cugell and Robson, 1966). Stimulating Y-cells with contrast-reversed gratings leads to frequencydoubled responses (Enroth-Cugell and Robson, 1966; Hochstein and Shapley, 1976), and the remote stimulation of the receptive field changes the responsiveness of the center (McIlwain, 1964; Krüger and Fischer, 1973). In spite of the fact that these effects have been intensively studied, their origin is still unknown.

Previous studies suggested a common linear receptive field for X- and Y-cells resulting from bipolar cell input (Kuffler, 1953; Rodieck and Stone, 1965). In addition, there is strong evidence that Y-cells receive input from small nonlinear receptive field subunits (Hochstein and Shapley, 1976; Victor, 1988). It is believed that amacrine cells form these subunits (Fisher et al., 1975; Hochstein and Shapley, 1976; Frishman and Linsenmeier, 1982), and several nonlinear responding amacrine cell types have been identified (Freed et al., 1996). The specific cell type or circuitry is

Received Feb. 26, 2002; revised July 11, 2002; accepted July 12, 2002.

This work was supported by a Scottish higher education funding council research development grant from the Institute for Neuronal Computational Intelligence and Technology (M.H.H., F.W.), European Commission grant Early Cognitive Vision (M.H.H., F.W.), and the Deutsche Forschungsgemeinschaft (Sonderforschungsbereich 509/A2; K.F.). We thank H. Wässle for his helpful comments and Paul Dudchenko for correcting the English. Many thanks also to our two reviewers for their helpful and detailed reviews.

Correspondence should be addressed to Matthias H. Hennig, Institute for Neuronal Computational Intelligence and Technology, Department of Psychology, University of Stirling, Stirling, FK9 4LA, UK. E-mail: hennig@cn.stir.ac.uk. Copyright (C) 2002 Society for Neuroscience $0270-6474 / 02 / 228726-13 \$ 15.00 / 0$ still under debate, and there is evidence that nested feedback from narrow- and wide-field amacrine cells onto bipolar cell axon terminals contributes to nonlinear responses (Roska et al., 1998; Passaglia et al., 2001). However, a recent study in which parts of the retinal circuitry were inactivated pharmacologically provides evidence that amacrine cells are less important for the generation of nonlinear responses (Demb et al., 2001).

As an alternative hypothesis, it has been suggested that nonlinear ganglion cell responses could arise from the response properties of photoreceptors (Gaudiano, 1992a,b). This assumption was derived from a modeling study in which a specific push-pull circuitry along with the wide receptive field of Y-cells was found to be the main source of nonlinear behavior.

In the current study, we have designed a detailed model of the vertebrate retina to examine the origin of nonlinear behavior of ganglion cells. By quantifying the contributions of a realistically modeled photoreceptor and a nested amacrine circuit to ganglion cell nonlinearities, we show that both have a distinctive influence on the linearity of ganglion cell responses.

We show that although amacrine cells contribute to nonlinear responses, a photoreceptor nonlinearity is sufficient to reproduce frequency-doubled responses in Y-cells. Nonlinearities from different sources interact in a multiplicative way, and the influence of the amacrine circuit is $\sim 25 \%$ weaker than that of the photoreceptor.

Preliminary results have been published in abstract form (Hennig et al., 2001).

\section{MATERIALS AND METHODS}

Stimuli. As stimuli, noncolored luminance-modulated full-field flashes and sinewave gratings were used. Except where noted, 100\% Michelson contrast was used. The sine gratings were contrast-reversed with a temporal frequency of $4 \mathrm{~Hz}$ and a spatial frequency varying between 0.25 and 5.56 cycles per degree (cpd). 
Structure of the model retina. The model is mainly based on data from the light-adapted cat retina. Model neurons are arranged on a twodimensional, regular hexagonal grid representing $4.8^{\circ}$ by $4.8^{\circ}$ visual angle of the area centralis. Details of the cell models are given below. Distance between two photoreceptors was chosen as $6 \mu \mathrm{m}$, assuming an estimated photoreceptor density of 25,000 cones $/ \mathrm{mm}^{2}$ (area centralis; Steinberg et al., 1973; Wässle and Boycott, 1991). This distance corresponds to a visual angle of $\sim 1.7$ arcmin (Vakkur and Bishop, 1963). Optical blurring has been included by attributing a Gaussian-shaped spatial sensitivity profile to each photoreceptor with a SD of 6 arcmin (Smith and Sterling, 1990). A schematic diagram of the model is shown in Figure $1 A$, and its connectivity is described in the legend. Our analysis focuses on Oncenter cells, because the corresponding literature data allows for quantitative modeling of this cell class, whereas less is known about Off-center cells (see Discussion).

The simulation software has been developed in $\mathrm{C}++$, and simulations were performed on Intel x86/Linux systems. The Euler method was used for integration with a time step of $0.1 \mathrm{msec}$. For data analysis, Matlab programs were used.

Photoreceptor. Photoreceptors are implemented in the model by means of a state-variable description, which allows inclusion of all important details of the signal transduction process (for review, see McNaughton, 1990; Müller and Kaupp, 1998; Fain et al., 2001). Details like the partition of the photoreceptor into outer and inner segments as well as spatial concentration gradients of ions and proteins are not considered. The model is, therefore, similar to a previous mathematical description of the photocurrent after brief stimulation (Schnapf et al., 1990; Hennig and Funke, 2001).

In the outer segment of a photoreceptor, light-sensitive rhodopsin molecules become activated by photons. This is followed by two sequential stages that amplify the signal by a factor of $\sim 1,000,000$. At the end of the cascade, the enzyme phosphodiesterase is activated $\left(P D E \rightarrow P D E^{*}\right)$. This step is expressed by:

$$
\tau_{\text {Casc }} \frac{d\left[P D E^{*}\right](t)}{d t}=S(t)-\left[P D E^{*}\right](t),
$$

where $\left[P D E^{*}\right](t)$ denotes the concentration of activated PDE, S $(\mathrm{t})$ the stimulus and $\tau_{\text {Casc }}=10 \mathrm{msec}$ a time constant. Equation 1 implements a temporal low-pass filter. The activated PDE triggers a second cascade that generates the electrical response in the photoreceptor. The second messenger cGMP, which keeps open the cation channels in the cell membrane, is hydrolyzed by PDE. This leads to closure of the cationchannels $\left(\mathrm{Ca}^{2+}, \mathrm{Na}^{+}, \mathrm{K}^{+}\right)$and thus to a hyperpolarization. The concentration of hydrolyzed cGMP $\left(1-\left[5^{\prime} G M P\right]\right)=[c G M P]$ depends on the concentration of activated PDE and free calcium ions in the photoreceptor $\left(\left[\mathrm{Ca}^{2+}\right]\right)$. It is calculated by:

$$
\frac{d[c G M P](t)}{d t}=\frac{-\beta \cdot\left(\left[\mathrm{Ca}^{2+}\right](t)-1\right)}{\text { resynthesis }} \frac{-\left[P D E^{*}\right](t) \cdot[c G M P](t),}{\text { stimulus induced }}
$$

where $\beta=0.6 \mathrm{msec}^{-1}$ expresses the strength of the resynthesis reaction of cGMP. The resynthesis depends on the intracellular concentration of $\mathrm{Ca}^{2+}$ via the enzyme guanylyl cyclase (GC), which in turn is activated by guanylyl cyclase-activating protein (GCAP). This reaction can only take place when GCAP does not bind to $\mathrm{Ca}^{2+}$ ions, and thus only occurs when
the intracellular $\mathrm{Ca}^{2+}$ concentration is low. The intracellular $\mathrm{Ca}^{2+}$ concentration is given by:

$$
\frac{d\left[\mathrm{Ca}^{2+}\right](t)}{d t}=\frac{\gamma(1+c \cdot([c G M P](t)-1))}{\text { influx }} \quad \frac{-\alpha \cdot\left[C a^{2+}\right](t) .}{\text { efflux }}
$$

The constants $\alpha=0.2 \mathrm{msec}^{-1}$ and $\gamma=0.2 \mathrm{msec}^{-1}$ denote the rates of efflux and influx of ions. The light response changes the cation concentration by $\gamma c([c G M P](t)-1)$, which leads to a change of the membrane potential. The constant $c=0.42 \mathrm{msec}^{-1}$ expresses the impact of [cGMP] on the cation concentration.

The constants in Equations 1-3 were fitted to existing data from the literature. Of all ionic species involved in phototransduction, only the intracellular concentration of $\mathrm{Ca}^{2+}$ was modeled explicitly, because it mediates the resynthesis of cGMP. Equations 2 and 3 form a system of first order coupled linear differential equations whose solutions provide a nonlinear relation between the stimulus intensity and the response of the photoreceptor.

Because the temporal shape of photocurrent and photovoltage $V_{\mathrm{P}}$ differ significantly, voltage-dependent currents are likely to shape the responses of the photoreceptors. As shown experimentally, a hyperpolarization-activated current has a strong impact on photovoltage (Bader and Bertrand, 1984; Demontis et al., 1999). It was modeled by:

$$
\frac{d[H](t)}{d t}=\left(\frac{\lambda_{H}}{e^{\left(V_{P}(t)-A_{H}\right) S_{H}}+1}\right) \cdot(1-[H](t))-\delta_{H_{\tau}}[H](t),
$$

where $A_{\mathrm{H}}=40 \mathrm{mV}$ defines the activation of the receptor at which the current is half-activated, and $S_{\mathrm{H}}=10 \mathrm{mV}^{-1}$ gives the slope of the activation function. The constants $\lambda_{\mathrm{H}}=1 \mathrm{msec}^{-1}$ and $\delta_{H_{\tau}}=0.025$ $\mathrm{msec}^{-1}$ define the rates of increase and decay of the ionic concentrations.

Finally, the membrane potential of the photoreceptor is computed by:

$$
C_{P} \frac{d V_{P}(t)}{d t}=q_{P} \frac{d[C a](t)}{d t}+q_{I} \frac{d[H](t)}{d t}
$$

where $C_{\mathrm{P}}=1 \mu \mathrm{F} / \mathrm{cm}$ is the membrane capacity and $q_{\mathrm{P}}=10^{6} \mathrm{C}$ and $q_{\mathrm{I}}=$ $6 \times 10^{5} \mathrm{C}$ are constants that define the amount of unit charge transported by the ionic currents.

Neuron models and synaptic coupling. All remaining retinal neurons were implemented according to the membrane equation for a passive neural membrane (Wörgötter and Koch, 1991) given by:

$$
\tau \frac{d V(t)}{d t}=R \cdot\left(\sum_{i=0}^{N} g_{i}(t) \cdot\left(E_{i}-V(t)\right)\right)+V_{\text {rest }}-V(t),
$$

where $\tau$ is the membrane time constant, $g_{\mathrm{i}}(t)$ the conductances evoked by the synapses, $E_{\mathrm{i}}$ the reversal potential for the input $i, R$ the membrane resistance, and $V_{\text {rest }}$ its resting potential. The input conductances are linear functions of the presynaptic potential, which is expressed as $R \times$ $g_{\mathrm{i}}(t)=\lambda \times V_{\text {pre. }}$ The constant $\lambda=20 \mathrm{~V}^{-1}$ defines a scaling factor. For the excitatory inputs, mediated by glutamate, the reversal potential has been set to $E_{\text {rev,exc }}=0 \mathrm{mV}$ for all cell types. The resting potential of all cell types has been set to $V_{\text {rest }}=-60 \mathrm{mV}$.

Electrical synapses were modeled by assuming that neighboring neurons are coupled by a constant resistance and membrane impedance (for a more detailed analysis, see Oshima et al., 1995). In that case current injection into the cell leads to a spatial decay of the membrane potential, which was assumed to be Gaussian-shaped. The activity $V_{\mathrm{HC}}$ of a cell in an electrically coupled network is then given by:

$$
\tau \frac{d V_{H c}(t)}{d t}=R \sum_{x, y} V_{P}(\vec{x}) \cdot G_{\sigma}(\vec{x}) \cdot\left(E_{i}-V_{H c}(t)\right)+V_{r e s t}-V_{H C}(t),
$$

where $\tau$ is the membrane time constant, $V_{P}(\vec{x})$ the activity of the presynaptic cell at location $\vec{x}$ and $G(\vec{x})$ a Gaussian convolution kernel with the $\mathrm{SD} \sigma$, which is centered above the cell. Specific parameters are given in Table 1.

Horizontal cells. Horizontal cells receive feedforward, sign-conserving connections from the photoreceptors. Here, the achromatic A-type horizontal cell (Wässle et al., 1978), which solely contacts cones, has been modeled. Horizontal cells are interconnected by gap junctions, as modeled by Equation 7. The receptive field width has been set to $\sigma=0.72^{\circ}$. This corresponds to a responsive length (length constant) of the cell in the range of $200-450 \mu \mathrm{m}$ (Nelson, 1977), equivalent to $\sim 1-2^{\circ}$ of visual angle.

Bipolar cells. Bipolar cells receive feedforward (sign-conserving: Off; sign-inverting: On) connections from photoreceptors and antagonistic input from the closest horizontal cell, which leads to a difference-ofGaussian (DOG)-shaped receptive field structure (Dacey et al., 2000). It is still unclear how the surround of On-center bipolar cells is formed. Two possibilities are discussed in the literature: either the surround is mediated by an inhibitory connection to the cone axon terminal (Satoh et al., 2001) or the reversal potential for $\mathrm{Cl}^{-}$is positive to the resting potential in bipolar cell dendrites. The latter would cause a depolarizing response to GABA (Vardi et al., 2000). Within the framework of a model based on the membrane equation, these two possibilities are equivalent if the nonlinear voltage-dependent currents in the cone are neglected. Thus, in our model, the horizontal to bipolar connection was imple- 

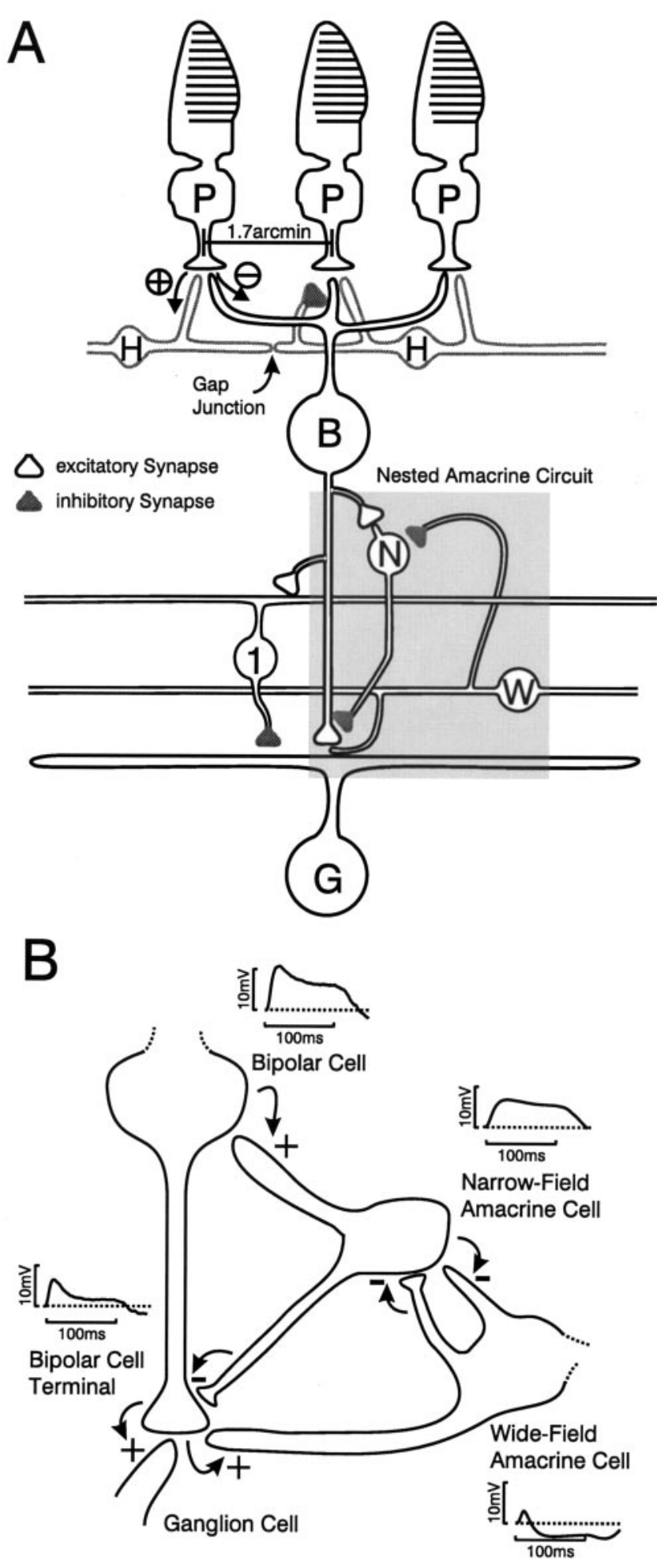

Figure 1. A, Schematic circuit diagram of the model. Shown are the different cell types and their synaptic connections for the Y-On pathway. Photoreceptors $(P)$ connect by excitatory synapses $(+)$ to horizontal cells $(H)$ and sign-inverting synapses $(-)$ to bipolar cells $(B)$. The horizontal cell to bipolar cell connections mediate the surround of the receptive field of bipolar cells (Dacey et al., 2000). The classical receptive field for ganglion cells $(G)$ is composed of excitatory bipolar cell input to the receptive field center and inhibitory input from type- 1 amacrine cells to the surround (Flores-Herr et al., 2001). For Y-cells, the nested amacrine circuit (shaded in gray) has been included, which consists of narrow-field $(N)$ and wide-field $(W)$ amacrine cells (Roska and Werblin, 2001; Pas- mented by inverting the horizontal cell response at the resting potential and calculating the postsynaptic current assuming a reversal potential of a GABA $_{C}$ synapse (Feigenspan et al., 1993). A convergence of seven cones on one bipolar cell has been assumed in the model (Cohen and Sterling, 1991), and the surround radius equals the receptive field width of a horizontal cell.

Additionally, the axon terminal of the subset of bipolar cells that contact only Y ganglion cells is inhibited by a narrow field amacrine cell (see below). This functional connectivity that establishes a subset of bipolar cells, termed "transient bipolar cells" because of their pronounced transient responses, is supported by physiological studies (Nirenberg and Meister, 1997; Roska et al., 1998; Marc and Liu, 2000) (but see Awatramani and Slaughter, 2000). In cat retina, this could reflect the difference between the sustained bipolar cell types b2/b3 and the transient type b1 (Freed, 2000).

Amacrine cells. Three functionally different amacrine cell types have been included in the model. All amacrine cells are inhibitory. The first type (dubbed type-1 amacrine) is a GABAergic interneuron with a wide receptive field that receives excitatory input from bipolar cells and inhibits ganglion cells, as shown experimentally (Flores-Herr et al., 2001). It is thereby substantially contributing to the surround of $X$ - and Y-cells.

The remaining two types are wide- and narrow-field amacrine cells that form a circuit that truncates the input of Y-cells (Fig. 1B). The wide-field amacrine cell receives excitatory input from the transient bipolar cell terminals and inhibitory input from narrow field amacrine cells. Its receptive field is Gaussian-shaped with $\sigma_{\mathrm{C}}=0.50^{\circ}$. The narrowfield cell receives excitatory input from bipolar cells and inhibitory input from the nearest wide-field amacrine cell. Their receptive field consists of a Gaussian-shaped excitatory region with $\sigma_{\mathrm{C}}=0.12^{\circ}$. It has been shown that this specific circuit contributes to the transient responses of ganglion cells (Roska et al., 1998). Responses to full-field flashes indicate this (Fig. 1B, small insets). Here we find that the pathway from the bipolar cell through the narrow-field amacrine cell to the bipolar cell terminal has a delayed inhibitory effect, reducing the late tonic response. The wide-field cell disinhibits the bipolar cell terminal at stimulus onset, thus further enhancing the early part of the response in the bipolar cell terminal. Clear-cut evidence that this circuit enhances transients and thereby contributes to nonlinear behavior, however, only exists for the Salamander retina (Roska et al., 1998).

Ganglion cells. Two types of ganglion cells have been implemented, one type with a narrow receptive field (X-cells) and another type with a wide receptive field (Y-cells) (Enroth-Cugell and Robson, 1966), analogous to the morphological classification as $\beta$ and $\alpha$ cells (Boycott and Wässle, 1974). In this study we have focused on On-center ganglion cells. Off-center cells will only be mentioned in the Discussion. On-center cells receive excitatory input from On-bipolar cells, which form the center, and inhibitory input from type-1 amacrine cells, which form the surround of the receptive field. The center and surround input is weighted by two overlapping Gaussian profiles (Rodieck and Stone, 1965), where the surround input extends $>3.3$ times the center input for all types (Linsenmeier et al., 1982; Lee et al., 1998, for the primate). The center sizes are based on anatomical studies (Freed and Sterling, 1988; Cohen and Sterling, 1991) and correspond to a convergence of 37 cones for the $\mathrm{X}$-cell and 312 cones for the Y-cell (Table 1). The nested amacrine circuit is included in the presynaptic circuitry only for Y-cells.

\section{RESULTS}

\section{Photoreceptor responses}

In Figure 2 we show simulated photoreceptor responses. The top row demonstrates the nonlinear characteristic of the responses, which will be one central aspect used to explain the nonlinear behavior of ganglion cell responses. Figure 2, $E$ and $F$, compares

\section{$\leftarrow$}

aglia et al., 2001). The X-On pathway is identical to the Y-On pathway but omits the nested amacrine circuit. $B$, The nested amacrine circuit in detail. A narrow-field amacrine cell receives input from a bipolar cell and inhibits this bipolar cell at the axon terminal. A wide-field amacrine cell receives excitatory input from the bipolar cell axon terminal. Between both amacrine cell classes reciprocal inhibitory connections exist. The insets show the response of each cell to a full-field flash $(100 \mathrm{msec})$. 
Table 1. Parameters used in the simulations

\begin{tabular}{|c|c|c|c|c|}
\hline & $\sigma_{\mathrm{c}} / \mathrm{deg}$ & $\sigma_{\mathrm{s}} / \mathrm{deg}$ & $E_{\text {rev,inh }}(\mathrm{mV})$ & $\tau(\mathrm{msec})$ \\
\hline Horizontal cell & $0.72^{a}$ & - & - & 20 \\
\hline Bipolar cell & $0.12^{b}$ & $0.72^{c}$ & $-70^{d}$ & 10 \\
\hline Transient bipolar cell terminal & $0.12^{e}$ & $0.72^{e}$ & $-70^{f}$ & 10 \\
\hline Wide-field amacrine cell & 0.50 & - & $-70^{g}$ & 10 \\
\hline Narrow-field amacrine cell & 0.12 & 0.50 & $-70^{h}$ & 10 \\
\hline Type- 1 amacrine cell & 0.12 & - & - & 10 \\
\hline $\mathrm{X}$-ganglion cell & $0.18^{i}$ & $0.59^{j}$ & $-70^{k}$ & 10 \\
\hline Y-ganglion cell & $0.50^{i}$ & $1.65^{j}$ & $-70^{k}$ & 10 \\
\hline
\end{tabular}

The receptive field center $\left(\sigma_{\mathrm{c}}\right)$ and surround $\left(\sigma_{\mathrm{s}}\right)$ radius is the anatomic extend of the subfield that receives synaptic input. $E_{\text {rev,inh }}$ is the reversal potential for inhibitory synaptic transmission, based on studies in which perforated patch pipettes were used. $\tau$ is the membrane time constant.

${ }^{a}$ Nelson, 1977.

${ }^{b}$ Cohen and Sterling, 1991 .

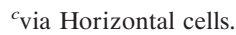

${ }^{d} \mathrm{GABA}_{\mathrm{C}}$; Feigenspan et al., 1993; see Materials and Methods.

${ }^{e}$ Identical to bipolar cell.

${ }^{f} \mathrm{GABA}_{\mathrm{C}}$; Roska et al., 1998.

${ }^{g} \mathrm{GABA}_{\mathrm{A}}$; Flores-Herr et al., 2001.

${ }^{h}$ Glycine; Flores-Herr et al., 2001.

${ }^{i}$ Cohen and Sterling, 1991; Freed and Sterling, 1988.

${ }^{j}$ Linsenmeier et al., 1982.

${ }^{k} \mathrm{GABA}_{\mathrm{A}}$; Flores-Herr et al., 2001.
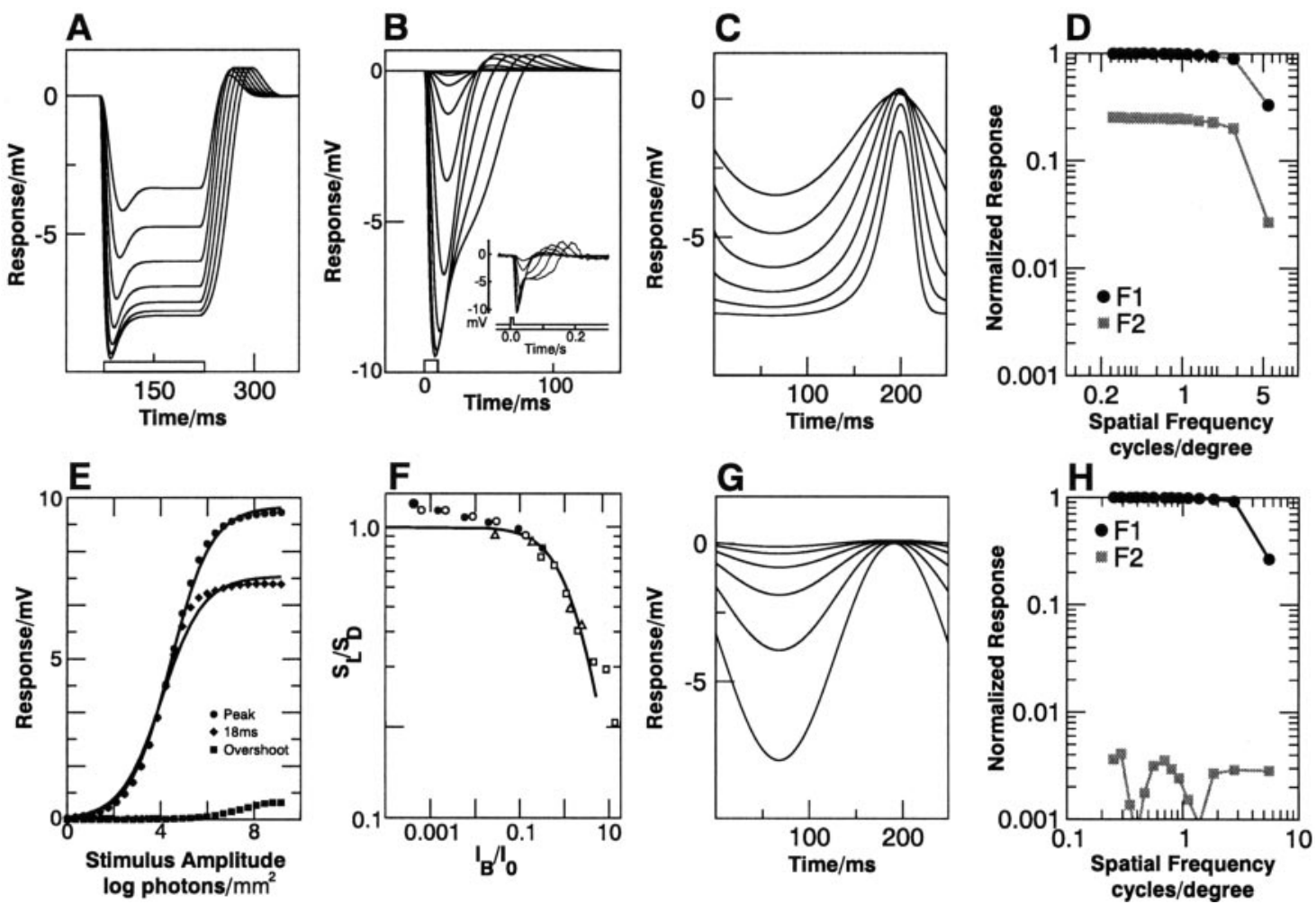

Figure 2. Characteristics of the simulated photoreceptor. $A-C$, Responses to a flash $(A, 150 \mathrm{msec} ; B, 10 \mathrm{msec}$, stimulus marked by boxes on bottom $)$ and to sinusoidally modulated luminance $(C, 4 \mathrm{~Hz})$ at different light intensities $\left(3.5-7 \log\right.$ photons $\left./ \mathrm{mm}^{2}\right)$. The inset in $B$ shows data from a macaque cone (modified from Schneeweis and Schnapf, 1999). D, The first (F1) and second (F2) harmonic response component at different spatial frequencies. The stimulus was a sinusoidally modulated sine grating with a mean luminance of 4 log photons $/ \mathrm{mm}^{2}$ and the $90^{\circ}$ phase centered above the cell. The drop-off at high spatial frequencies is caused by the spatial blurring of the stimulus. $E$, The response amplitude of the photoreceptor as function of the light intensity, measured at the peak (circles), $18 \mathrm{msec}$ after stimulus onset (squares), and at the peak of the depolarization after stimulus offset (diamonds). Stimulus was a $10 \mathrm{msec}$ flash. The lines show fits with the Michaelis Menten function $R=R_{\max }\left(I / I+I_{0}\right)$, where $R_{\max }$ is the maximal, $R$ the actual response amplitude, $I$ the stimulus intensity, and $I_{0}$ the stimulus intensity that leads to a half maximal response. $F$, Flash sensitivity of the simulated photoreceptor (line) and data from four different cones from the macaque (data taken from Schneeweis and Schnapf, 1999). Sensitivity $S_{\mathrm{L}}$ is expressed as the response divided by the flash intensity and is normalized by the dark-adapted sensitivity $S_{\mathrm{D}}$. The abscissa is in units of the background intensity $I_{\mathrm{B}}$ divided by the background intensity that halves $S_{\mathrm{D}}, G$, Response of the "linear" photoreceptor model to sinusoidally modulated luminance (stimulus as in $C$ ). $H$, Spatial frequency tuning curve of the "linear" photoreceptor model (stimulus as in $C$ ). 


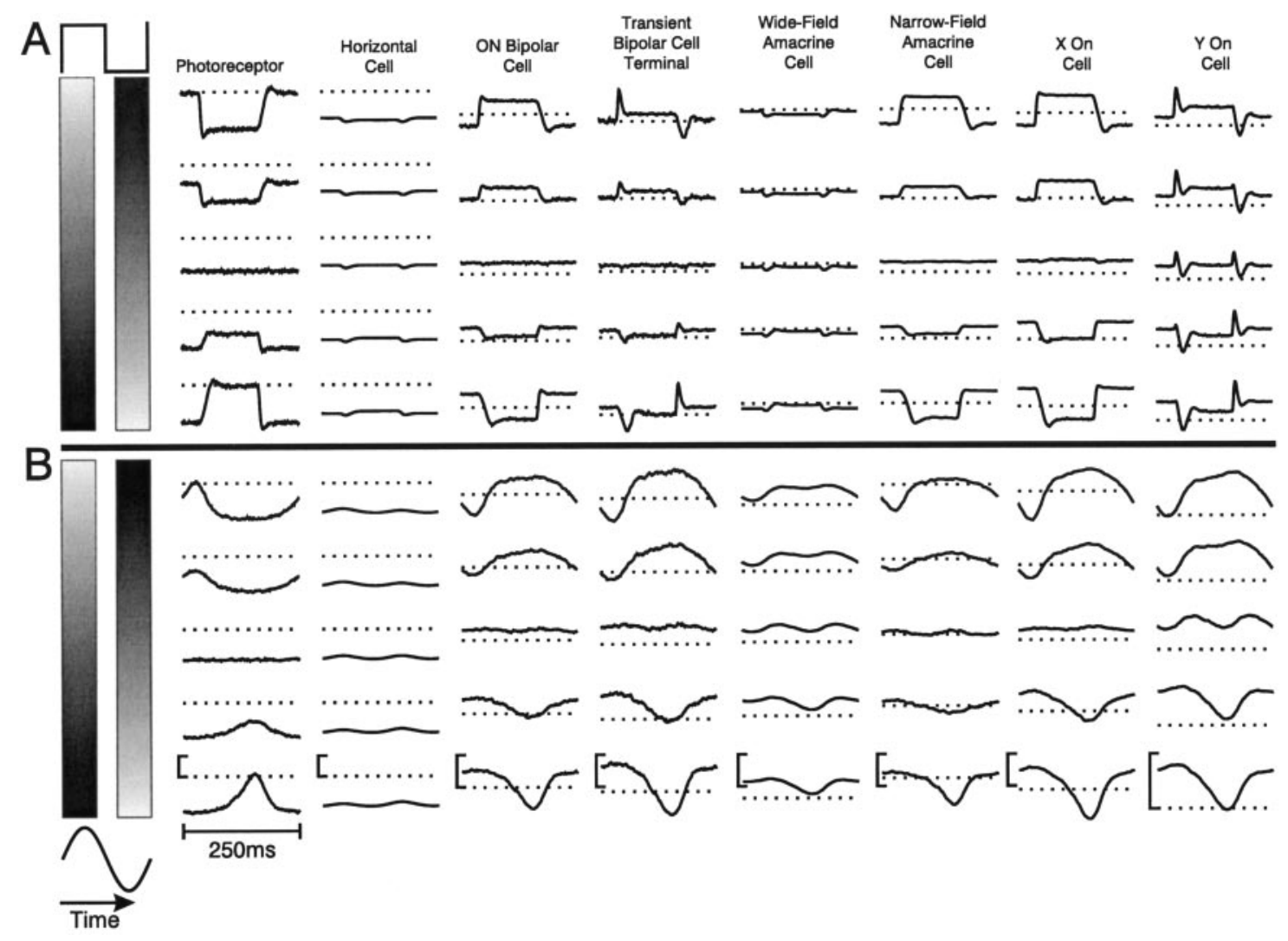

Figure 3. Responses of the different simulated cell types to stimulation with a counterphasing $(A)$ and sinusoidally modulated $(B)$ sine wave grating $(0.8 \mathrm{cpd})$. The vertical position of the responses indicates the location of the cells relative to the spatial stimulus phase, as shown on the left margin. Dotted horizontal lines indicate the dark potential of each cell type. The vertical calibration bars at the bottom indicates $5 \mathrm{mV}$. In this case, the second harmonic component of the wide-field amacrine cell and Y-cell reaches 70 and 50\% of the first harmonic amplitude, respectively.

simulated to real photoreceptor characteristics. In Figure 2, $G$ and $H$, we show how a linearized photoreceptor behaves. Such an artificially altered response characteristic provides us with an excellent tool for circuit dissection by allowing us to differentiate photoreceptor-induced from other nonlinearities. Typical responses of our model photoreceptor are shown in Figure $2 A-C$. The response to a flash (Fig. $2 A, B$ ) shows a sharp initial transient hyperpolarization of the membrane potential, which is followed by a sustained response and terminated by a short depolarization at light offset. This behavior is very similar to recordings of the photovoltage from the macaque cone photoreceptor (Schneeweis and Schnapf, 1999) (Fig. 2B, inset) apart from a slightly slower repolarization in the macaque data at high luminance of unknown origin. Similar to the responses to flashes, a sinusoidal modulation of the luminance (Fig. $2 C$ ) leads to a pronounced asymmetry between the light and dark phase of the response. As shown for rods, this harmonic distortion is caused partially by the $I_{\mathrm{h}}$ current that we included in the model photoreceptor (Demontis et al., 1999). It is also reflected in the Fourier analysis of the responses. The strong second harmonic component in Fig. $2 D$ indicates a substantial distortion of the stimulus.

To further validate the photoreceptor model, we have tested whether the Michaelis Menten function and Webers law for background desensitization, which are found in many species (McNaughton, 1990; Fain et al., 2001), could be reproduced (Fig. $2 E, F)$. In close correspondence with experimental data measured by Schnapf et al. (1990) and Schneeweis and Schnapf (1999), the saturation of the response indeed fulfills the Michaelis Menten relation (Fig. 2E). The decrease of the flash sensitivity with increasing background illumination is also in accordance with experimental data (Fig. 2F) (Schneeweis and Schnapf, 1999).

Figure 2, $G$ and $H$, shows, in comparison, the behavior of the photoreceptor responses after linearization. Linearizing here means that the response amplitude of the receptor is modeled as a linear function of the stimulus luminance and does not saturate. Note that the second harmonic $(F 2)$ is virtually nonexistent for the linear photoreceptor in Figure $2 H$.

\section{Standard responses of all retinal cell types}

In Figure 3 we show results from simulated intracellular recordings from different retinal cell classes and the transient bipolar cell terminal. The diagram shows two sets of responses to either a counterphasing (Fig. $3 A$ ) or a sinusoidally modulated (Fig. $3 B$ ) grating stimulus at five different spatial phases. For cells located at the zero-phase of the stimulus (center traces) there is no mean luminance modulation across their receptive fields for every point in time. A photoreceptor placed at exactly this location will indeed not respond (Fig. 3A,B, leftmost-center traces). Significant second harmonic deviations from Null-responses are only found in the Y-cells and wide field amacrine cells (Fig. 3B).

The top and bottom traces represent the $\pm 90^{\circ}$ phases of stimulation, and accordingly responses are dominated by first harmonics in all but the horizontal cells. In wide-field amacrine cells and Y-cells, a substantial second harmonic distortion is observed.

Simulated horizontal cells behave somewhat differently. At first we observe that there are small, but still clearly visible second 


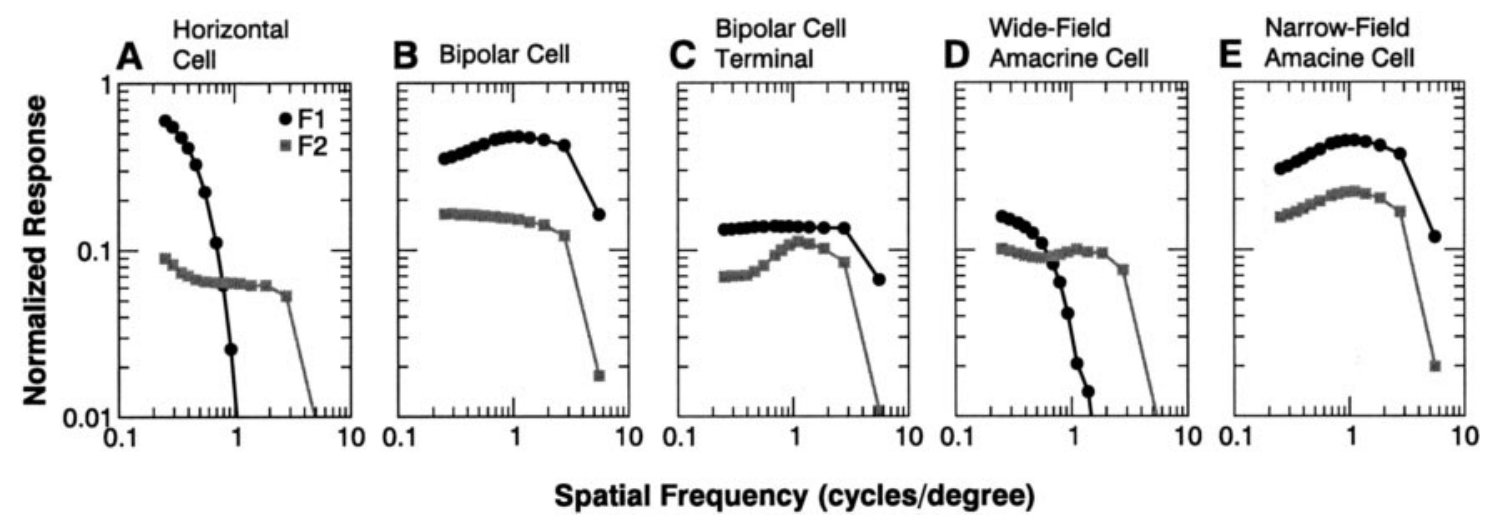

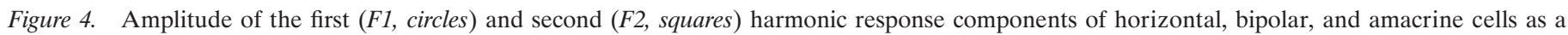

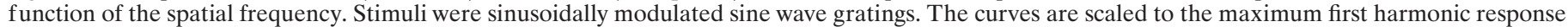
of the nonlinear photoreceptor in Figure $2 D$.

harmonic deviations from the Null response. Such tiny but distinct second harmonic responses are also clearly visible in the data of Lankheet et al. (1992, their Fig. 3). The first harmonic modulations are not visible in these responses, because the spatial frequency has been too high to stimulate the receptive field of horizontal cells.

The small second harmonics in the horizontal cells suggests that there is a nonlinear influence early in the retinal pathway, whereas the behavior of the wide field amacrine cells indicates additional, later occurring nonlinear input to the Y-cells. In general it seems that cells with wide receptive fields tend to show stronger deviations from the Null-response than cells with small receptive fields. As will be shown later, the receptive field size is indeed one important parameter for the linearity of retinal cells.

The transient bipolar cell terminal responds very phasic to a counterphasing grating (Fig. $3 A$ ). This is caused by the delayed inhibition of the amacrine pathway, which reduces the late, tonic response (Fig. 1B). Y-cells that receive input from transient bipolar cell terminals consequently respond more transiently than $\mathrm{X}$-cells. Another observation is that the maintained response to uniform stimuli as well as the mean response to gratings of Y-cells is smaller compared to that of X-cells. This is caused by the inhibition by the amacrine-bipolar cell circuit and is in accordance with experiments (Sato et al., 1976; Troy and Robson, 1992).

\section{Spatial frequency tuning of horizontal, bipolar, and amacrine cells}

Figure 4 shows the spatial frequency tuning curves for all modeled cell classes except photoreceptors and ganglion cells. The curves for the first and second harmonics intersect only for horizontal and wide-field amacrine cells. This indicates nonlinear behavior in these two cell types at spatial frequencies where the second harmonic response component exceeds the first harmonic component. It is especially pronounced in the wide-field amacrine cells, where the second harmonic is almost equally strong as the first even for the low spatial frequencies. The responses of the bipolar and narrow field amacrine cell, on the other hand, are largely linear.

For the simulated horizontal cell, the second harmonic response component is weaker than for the photoreceptor. At low spatial frequencies, it is a factor of 10 smaller than the first harmonic component. At $90 \%$ contrast, we find a ratio of 12 (data not shown). This is in accordance with experimental data
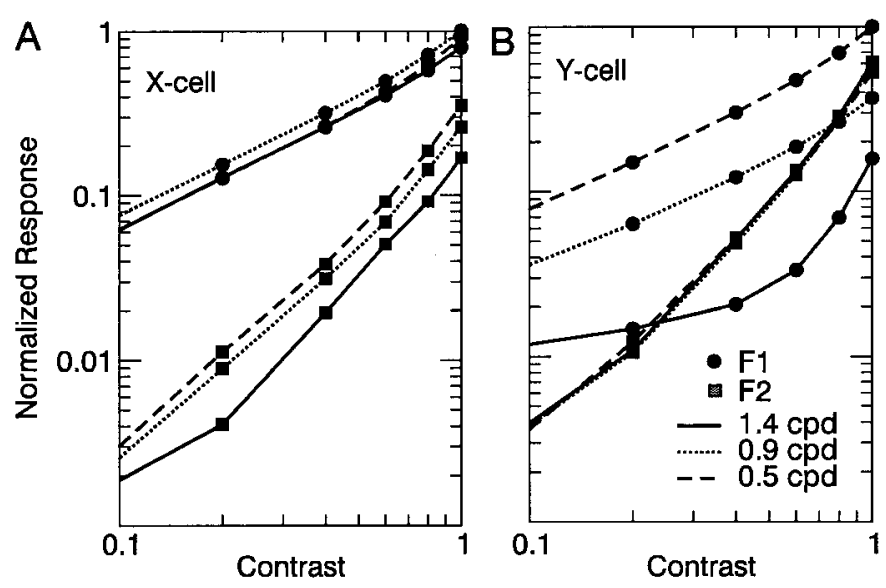

Figure 5. First (F1, circles) and second (F2, squares) harmonic response amplitudes of an X-cell $(A)$ and a Y-cell $(B)$ at different contrast levels. Stimuli were sinusoidally contrast reversed sine gratings at different spatial frequencies. The responses are normalized to the maximum of the strongest first harmonic response of each cell.

(Lankheet et al., 1992). Recent recordings from H1 horizontal cells in the macaque (Lee et al., 1999; Smith et al., 2001) show a similar harmonic distortion that we could reproduce using our photoreceptor model. On the other hand, we found that it was not possible to reproduce these responses using the linearized photoreceptor. This again supports the notion that horizontal cell nonlinearities derive from the photoreceptors.

As noted above, both wide-field amacrine and horizontal cells integrate over a rather large spatial area. As a consequence, they essentially collect and accumulate the asymmetrical parts of the photoreceptor responses, leading to second order peaks in their responses. The aspect of spatial integration of nonlinearities will also be central to the discussion of the spectra of Y-cells in the following sections. A schematic explanation of this effect can be found in the Discussion (see Fig. 11).

\section{Contrast sensitivity of ganglion cells}

Figure 5 shows the amplitudes of the first and second harmonic response component as a function of the contrast for simulated $\mathrm{X}$ - and Y-cells. For both cell types, the first harmonic increases monotonically and is approximately proportional to the contrast. In experimental studies under photopic conditions, the slope of this curve is typically lower (Troy et al., 1993), indicating that 
additional contrast gain control (Shapley and Victor, 1978), and adaptation mechanisms (Smirnakis et al., 1997) act in the retina that we have not been included in the model. The second harmonic responses increase more strongly with increasing contrast than the first harmonic and are stronger for Y-cells. For both cell classes, second harmonics are detectable from more than $\sim 20 \%$ contrast. This is close to the observed experimental threshold for second harmonics in Y-cells, which are detectable at just above 15\% contrast (Hochstein and Shapley, 1976).

\section{Spatial frequency tuning of ganglion cells and circuit dissection}

Figure 6 shows spatial frequency response curves (solid lines) obtained from the membrane potential of X-and Y-ganglion cells and from modified siblings of them, which were derived by changing some properties of the circuitry. All these modifications, which are described below, only affect the second harmonic of the responses; the first harmonic curves remain almost entirely unchanged.

First harmonic spatial frequency response curves for completely modeled $\mathrm{X}$ - and $\mathrm{Y}$-cells (Fig. $6 A, C$ ) closely resemble those reported in the literature (Fig. 6A,C, insets) (Freeman, 1991; Troy et al., 1993, 1999). Second harmonic responses for Y-cells match those reported for membrane potential recordings by Demb et al. (1999) but differ in shape from those studies that recorded action potentials (Enroth-Cugell and Robson, 1966; Hochstein and Shapley, 1976). This is a consequence of the half-wave rectified characteristic of the impulse rate functions, which cuts away the subthreshold part of the response. It leads to a strong attenuation of the second harmonic component at low spatial frequencies. To illustrate this, dashed lines in $A$ and $C$ show tuning curves after half-wave rectification.

The peak in the first harmonic response component results from the receptive field center size of the cell, which determines its spatial filtering characteristics. The second harmonic response shows that $\mathrm{X}$-cells respond fairly linearly over a wide range of spatial frequencies, whereas Y-cells behave nonlinearly at high spatial frequencies.

To investigate the different factors contributing to the nonlinearity of the simulated cells, we changed some properties of the model. Figure $6 B$ (as well as $D, F$ ) was obtained by linearizing the photoreceptor responses, while keeping all other parameters identical to those used in $A$ or $C$, respectively. This removes all nonlinear contributions of the photoreceptor to the network (see Fig. 2 for a comparison of the photoreceptor responses). For the $\mathrm{X}$-cell, this essentially leads to a uniform reduction of the second harmonic response components (Fig. 6, compare $B, A$ ), indicating that nonlinear responses are reduced in a similar way for all spatial frequencies. Y-cells also show a reduced second harmonic response (Fig. 6, compare $D, C$ ), but the nested amacrine circuit clearly affects the second harmonic response, so no simple downward shift is observed.

Figure $6 E$ represents a Y-cell modeled without the nested amacrine circuit, which we for simplicity call an "amacrinelesioned Y-cell." Within the constraints of our model, such a cell could be imagined as an X-cell with an overly large receptive field. Nevertheless, for high spatial frequencies, the second harmonic response dominates over the fundamental response. This supports the notion that the nonlinear behavior of ganglion cells is related to the receptive field size.

Linearization of the photoreceptor responses has, for an amacrine-lesioned Y-cell, exactly the same effect as for a normal
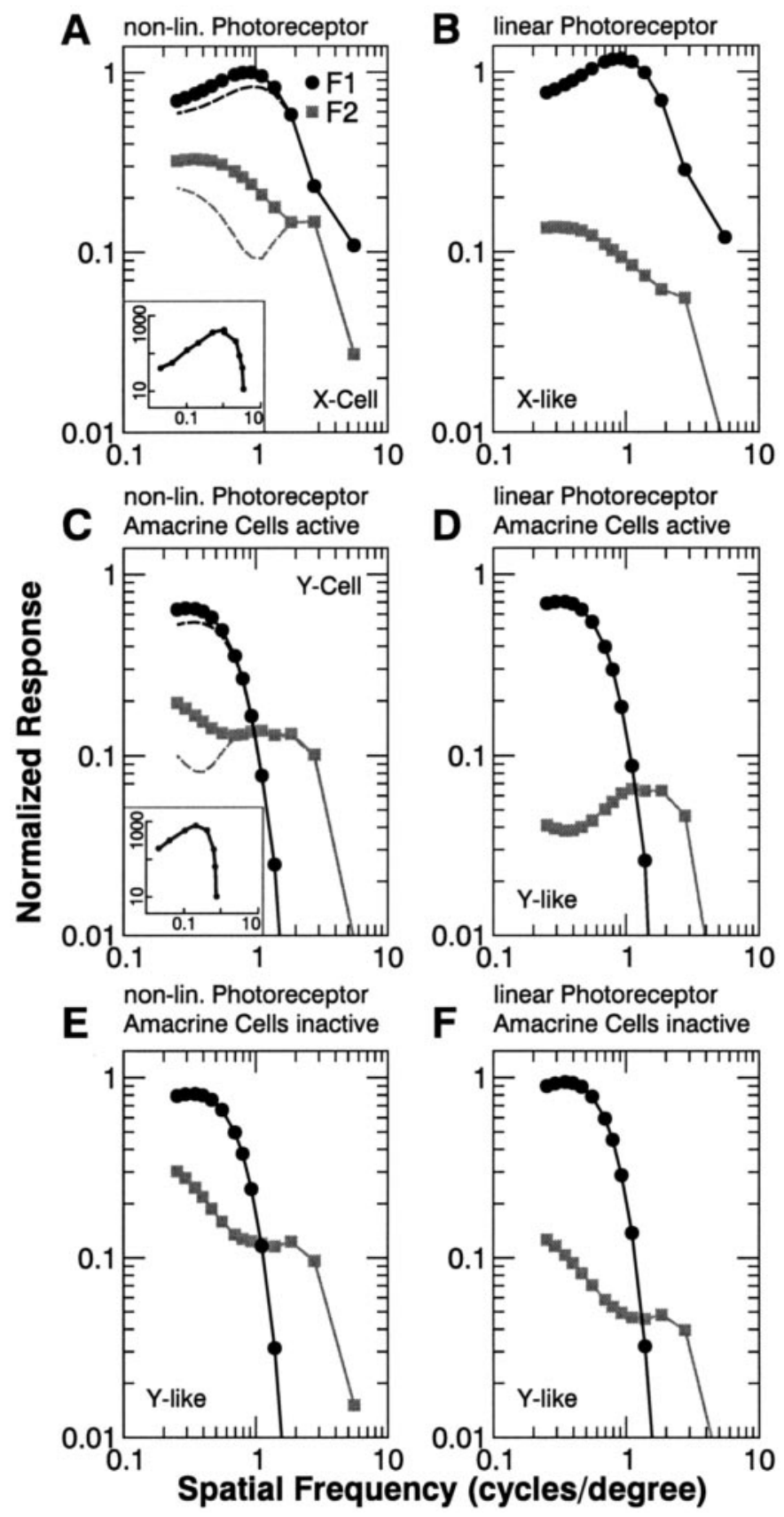

Figure 6. Amplitude of the first (circles, F1) and second (squares, F2) harmonic response components of an X-ganglion cell $(A)$ and a Y-ganglion cell $(C)$ and their modified siblings. The insets in $A$ and $C$ show first harmonic responses obtained experimentally [modified from Freeman (1991), their Fig. 1]. The X-like cell $(B)$ is identical to the X-cell apart from having used the "linear" photoreceptor model (Fig. 2). Y-like cells $(D-F)$ differ from the Y-cell with respect to the photoreceptor model and their presynaptic circuitry. The curves were obtained at maximum modulation (i.e., $90^{\circ}$ phase) with sinusoidally modulated gratings. All curves are scaled to the maximum first harmonic response of the $\mathrm{X}$-cell $(A)$. The dashed lines in $A$ and $C$ show the spatial frequency-tuning curves after rectification of the membrane potential at the resting level. Here we assume a linear relationship between membrane potential and spike rate.

X-cell: the second harmonic curve is again shifted downwards (Fig. 6, compare $E, F$ ). Note that, despite of these linearizations, a substantial second harmonic response still exists in both the $\mathrm{X}$ and Y-cell responses. This reflects the harmonic distortion caused 


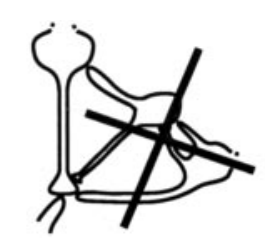

no Amacrine

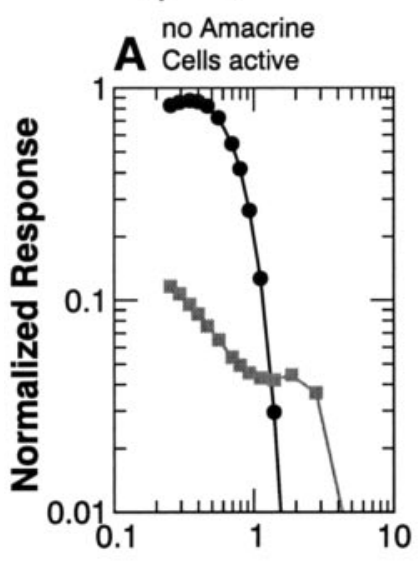

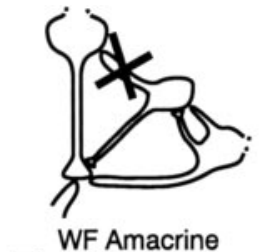

B Cell active only

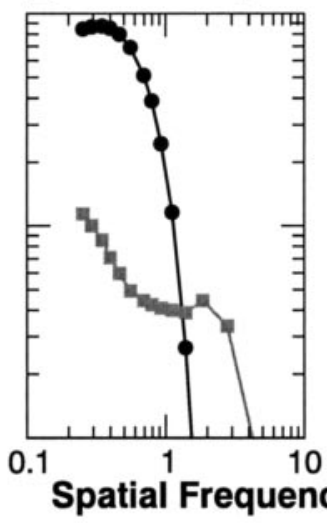

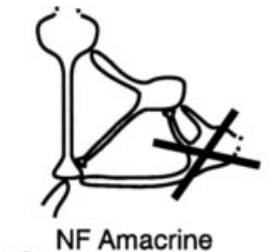

C Cell active only

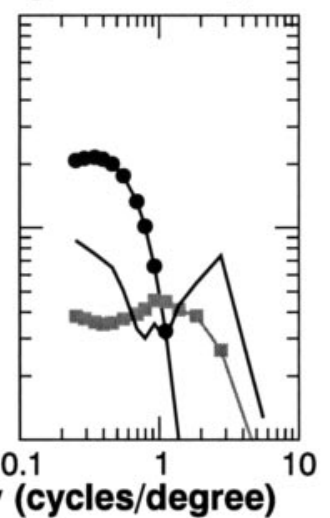

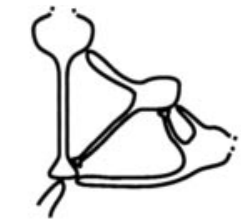

all Amacrine
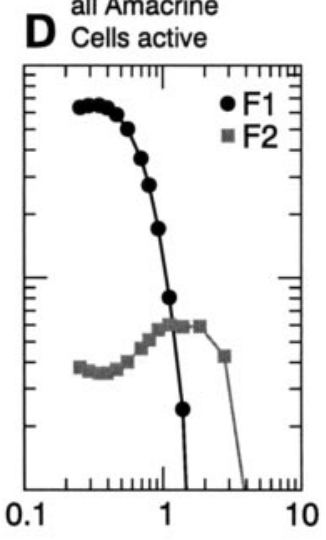

Figure 7. Amplitude of the first (circles, F1) and second (squares, F2) harmonic response components of a Y-like ganglion cell after inactivation of certain subcomponents of the nested amacrine circuit with the linear photoreceptor model. The same stimulus as in Figure 4 has been used, and curves are scaled to the maximum first harmonic response of the X-cell in Figure $6 A$. $A$ and $D$ are reproduced from Figure $6, F$ and $D$, and show the cases with inactivated and fully active nested amacrine circuit, respectively. In $B$ the excitatory input from the bipolar to the narrow-field cell is shut down, whereas the bipolar cell terminal still provides input to the wide-field amacrine cell. The negative output of the wide-field cell enters the narrow-field cell from which a recurrent negative connection exists. As a result, the narrow-field cell remains mainly hyperpolarized to the reversal potential of the inhibitory currents and does not inhibit the bipolar cell terminal. Therefore, the curves are almost identical to those in $A$. In $C$, the wide-field cell is shut down. This leads to a removal of disinhibition at the bipolar cell terminal and thus to a strong depression of the first harmonic component. In comparison with $A$ and $B$, we now also find a specific depression of the second harmonic at low frequencies. This behavior can be explained by second harmonic content of the membrane potential above the threshold introduced by the reversal potential of the inhibitory currents in the target cell (which is close to the resting potential) at different spatial frequencies. To visualize this influence, the thin curve in $C$ shows the second harmonic of the narrow-field cell obtained after half-wave rectifying the responses at the reversal potential. The second harmonic of the rectified response of the narrow-field cell is weak for medium-high spatial frequencies, because the narrow-field cell is partly hyperpolarized in this range. Thus, the thin curve is essentially a mirror image of the second harmonic curve of the ganglion cell, which reflects the fact that the narrow-field cell indirectly inhibits the ganglion cell.

by synaptic transmission, which was modeled by the passive neural membrane equation (Eq. 6). It shows that the often neglected boundary effects of the reversal potentials for ionic currents during synaptic transmission are also a potent source of nonlinearities.

Comparing the amacrine-lesioned Y-cell with a normal Y cell shows how the nested amacrine circuit affects the second harmonic responses. For the linearized cases (Fig. 6D,F), the effect is most clear. For low spatial frequencies, the nested amacrine circuit attenuates, and for high spatial frequencies it enhances the second harmonic component in the responses. A qualitatively similar but weaker effect occurs with a nonlinear photoreceptor (Fig. 6C,E).

Linearization of the photoreceptors as well as the removal of the nested amacrine circuit both act to linearize the responses. The overall magnitude of this effect, however, is different for both procedures, and it seems that linearization of the photoreceptors has a stronger influence relative to the removal of the amacrine circuit. This can be assessed by comparing Figure $6 C$ with $E$, which shows the rather mild influence of amacrine-lesioning, as opposed to a comparison of graphs Figure $6 C$ with $D$, where a much stronger, although nonuniform, drop of the curve of the second harmonic responses is visible.

\section{Dissecting the nested amacrine circuit}

To better understand the nonuniform influence of the nested amacrine circuit, we shut down some of its subcomponents and interpreted the resulting changes. To this end we only analyzed responses obtained at the ganglion cells with linearized photoreceptors. This allowed us to concentrate on the nested amacrine circuit as a source for nonlinearities.

The influence of the circuit subcomponents can be understood when comparing the partly active nested amacrine circuit (Fig. $7 B, C$ ) to the situation when it is fully shut down (Fig. 7A). First we observe that the curves in Figure $7, A$ and $B$, are almost identical, showing that wide-field cells alone do not influence linearity.

The situation is different in Figure $7 C$. Here only the narrowfield cell is active. We observe a strong general inhibition and a substantial attenuation of the second harmonics at low frequencies. Finally, the combined action of narrow- and wide-field cell leads to the shape of the curves in Figure $7 D$. For a detailed explanation of the underlying effects, see legend of Figure 7.

These results partly reproduce experimental results of Frishman and Linsenmeier (1982). In their study, the GABA antagonist picrotoxin had a similar attenuating effect on the frequency doubled responses that we observe when removing the GABAergic connections from the narrow-field amacrine cells to the bipolar cell terminals in the model $(\sim 40 \%$ decrease at high spatial frequencies) (Fig. 7A). We also found an enhancement of the first harmonic component of $\sim 50 \%$. The removal of the wide-field cell, which is in our model equivalent to the application of a strychnine also had an attenuating effect on the second harmonic 


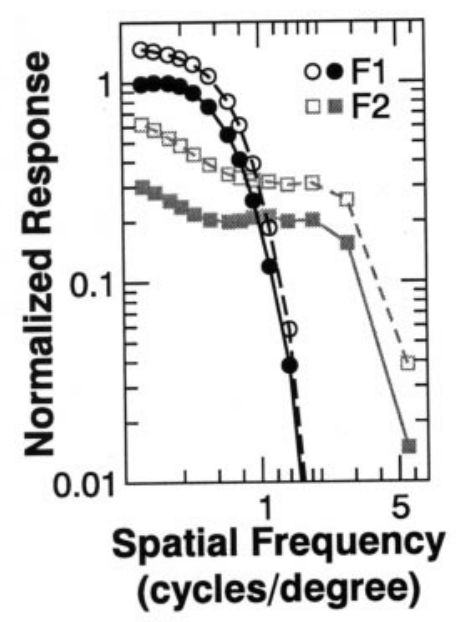

Figure 8. Spatial frequency-tuning curves of a simulated Y-cell ( filled symbols) and the same cell after blocking all inhibitory synapses in the inner retina (open symbols). Circles indicate the first (F1) and squares the second $(F 2)$ harmonic response component. Responses are scaled to the maximum of the first harmonic response of the Y-cell. The same stimulus as in Figure 4 has been used.

response $(20-40 \%$ reduction at high spatial frequencies) (Fig. $7 C)$. This is in contradiction to Frishman and Linsenmeier (1982), who report an increase of $\sim 200 \%$. This might be caused by direct glycinergic input on Y-cells which we have not included in the model (Freed and Sterling, 1988) or by effects that are caused by the injection of the antagonists into the cat's bloodstream. The first harmonic component, however, was attenuated to $\sim 50 \%$, which is again in accordance with Frishman and Linsenmeier (1982) results.

\section{Removing all inner retinal inhibition}

In a recent paper, Demb et al. (2001) have applied a mixture of specific GABA- (all types) and glycine-receptor antagonists to block all inhibition in the inner retina. They report an increase of the second harmonic response, especially at high contrasts. Accordingly, they conclude that the influence of amacrine cells on the nonlinearity of ganglion cell responses might be less strong than originally suggested.

In Figure 8 we simulate this experiment by shutting down the nested amacrine circuit and also the other remaining amacrine influence from the type- 1 amacrine cell (see Materials and Methods). This effectively creates a ganglion cell with a strongly reduced surround and with the center size of a Y-cell. We find that both first and second harmonic responses increase by approximately a factor of 1.5. This is in accordance with the findings of Demb et al. (2001). It seems, however, that elimination of innerretinal inhibition has basically a broad enhancing effect that affects all response components in the same way (see the first harmonic curve in Fig. 8).

\section{Influence of photoreceptor convergence on ganglion cell nonlinearities}

In Figure 6, $A$ and $E$, we had observed that part of the nonlinear behavior must result from the receptive field size, because these panels differed only in this respect. Accordingly, in Figure 9 we have investigated the complete cell models and their dissected versions by changing the receptive field size. This is equivalent to a change in the number of photoreceptors converging on the receptive field center. This particular parameterization of the receptive field size has been chosen because the receptive field size changes with retinal eccentricity as the photoreceptor density does, whereas the cone to ganglion cell ratio is less variable (Wässle and Boycott, 1991). It allows for a better comparison of $\mathrm{X}$ - and Y-cells at different eccentricities. In this way physiologically realistic X- and Y-cells (Fig. 9A,B, shaded regions) were created and many others that have unrealistic photoreceptor convergence numbers.

As before, we observed that the curves for the first harmonic are almost identical. The strong first harmonic response at a convergence number of $\sim 30$ photoreceptors reflects the match between the chosen stimulus frequency $(0.93 \mathrm{cpd})$ and the receptive field size. In addition, we found that in all cases the first harmonic dominates for small, and the second for large convergence numbers.

The main effect of the different circuit dissection procedures is a shift of the second harmonic curve along the ordinate, whereas the shape of the curve remains the same. Only for small convergence numbers a slightly different curvature is observed (Fig. 9, compare $A, B$ with $C, D)$. The highest values for the second harmonic response are obtained with nonlinear photoreceptors and an active amacrine circuit (Fig. 9B), which is a set of simulations containing the realistic Y-cells (shaded). The simulations with nonlinear photoreceptors but an inactive amacrine circuit (Fig. 9A), which contain the realistic X-cells (shaded), produce slightly stronger second harmonics than those with linear photoreceptors and an active amacrine circuit (Fig. 9D). The smallest values for the second harmonic are obtained, quite expectedly, for linear photoreceptors and an inactive nested amacrine circuit (Fig. 9C).

The location of the intersection between both curves is a suitable indicator of the "degree of nonlinearity" of the specific situation. Cells behave nonlinearly when the intersection occurs at small convergence numbers and vice versa. In Figure 10, the convergence number at which the intersection occurs is shown as a function of the spatial frequency of the stimulus for the different cases.

The top curve (1) represents the most linear case, modeled with the linear photoreceptor and an inactive amacrine circuit. The degree of parallel shift of the other curves relative to the top curve indicates the degree of nonlinearity introduced through the different circuit modifications. Curve 2 (linear photoreceptor + active amacrine circuit) is closer to the top curve than curve 3 (nonlinear photoreceptor + inactive amacrine circuit). Thus, across all spatial frequencies we find that the photoreceptor nonlinearity adds more to the nonlinear behavior of ganglion cells as compared with the nested amacrine circuit. The bottom curve, which belongs to the simulations with a nonlinear photoreceptor and active amacrine circuit, represents the most nonlinear case.

A mathematical analysis and comparison of the different cases revealed that the photoreceptor- and amacrine-induced nonlinearities interact approximately in a multiplicative manner (for an explanation, see the legend of Fig. 10). Thereby, the influence of the amacrine cells is $\sim 25 \%$ weaker than the photoreceptor.

\section{DISCUSSION}

In the present study we have designed a model to compare the influence of different properties of the retinal circuitry on the nonlinearity of ganglion cell responses. We focused on two pos- 


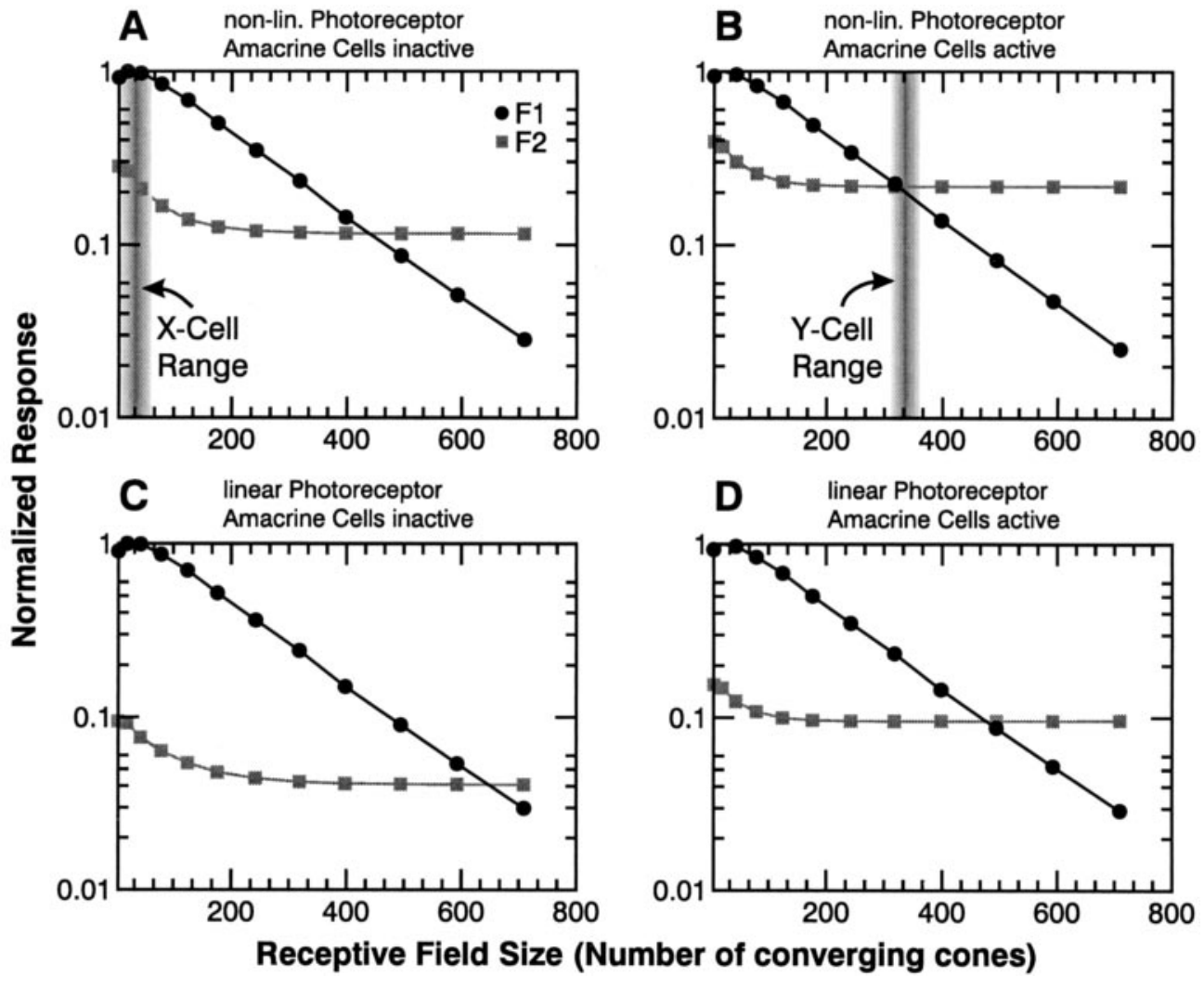

Figure 9. Normalized amplitudes of the first (circles, F1) and second (squares, F2) harmonic response component of ganglion cells as a function of the receptive field size. The receptive field size has been parameterized by the number of cones converging onto the receptive field center via bipolar cells. The stimulus was a sinusoidally modulated sine grating $(0.93 \mathrm{cpd}) . A$, Data for a ganglion cell without modeling the nested amacrine circuit (X-like). The shaded region indicates the convergence number for an $\mathrm{X}$-cell at $1^{\circ}$ eccentricity. $B$, Data for a ganglion cell including the nested amacrine circuit (Y-like). The shaded region indicates the convergence number for a Y-cell at $1^{\circ}$ eccentricity. $C, D$, Data for ganglion cells as in $A$ and $B$, respectively, but with a "linear" photoreceptor model. sible sources that can contribute to nonlinear ganglion cell behavior: (1) photoreceptor nonlinearities and (2) amacrine influences. Our main conclusion is that a large degree of the nonlinear behavior of Y-cells is a consequence of their larger receptive fields. This leads to a wider spatial integration of (nonlinear) photoreceptor responses relative to the smaller X-cells. The nested amacrine circuit, on the other hand, contributes less strongly and in a less uniform way to nonlinearities.

\section{Restrictions of the model}

The model introduced in this study was set up to capture the most important aspects of retinal anatomy and physiology, focusing on cat data. Other data were used where this was not available. In the following we will discuss some of the more relevant omissions of the model.

The model of the photoreceptor is an extension of a description of the photocurrent given by Schnapf et al. (1990). Its characteristics substantially contribute to the nonlinear responses of ganglion cells and thus the mathematical description and choice of parameters is crucial for the model behavior. The simplifications made here can be summarized as:

(1) The temporal properties of the amplification cascade regarding the activation and recovery of the involved messengers have been ignored as has pigment bleaching (for an analysis, see Laitko and Hofmann, 1998).

(2) All interactions between messengers have been temporally and spatially linearized to allow an easier mathematical treatment.

(3) Only one nonlinear current-voltage relation (the $I_{\mathrm{h}}$ current; Demontis et al., 1999) has been implemented. This is crucial for the shape of the initial transient of the response (for an extended analysis of ionic conductances in photoreceptors, see Yagi et al., 1997; Demontis et al., 1999).
However, as the model reproduces the most important characteristics of vertebrate photoreceptors (Fig. 2) we consider it sufficient in the context of the addressed questions.

Other cell classes are modeled in a conventional way by using the membrane equation (Wörgötter and Koch, 1991; Koch, 1999) and adding some cell specific characteristics to it. In general we found that our results are intrinsically consistent and robust to parameter variations in the physiological range.

The horizontal cell network has been simplified in two ways: first, the spatial spread of the activity is Gaussian-shaped, which is a sufficiently adequate estimate for horizontal cell receptive fields (Lankheet et al., 1990). Second, the feedback pathway to cones has been ignored. We used this approximation because the mechanisms that generate the horizontal cell receptive field are not yet understood. The main effect of this network is to produce a subtractive adaptation mechanism that relies on the mean light intensity by acting as antagonists in the bipolar cell receptive field.

Regarding their intrinsic properties, bipolar cells were modeled as a uniform class. Specific intrinsic mechanisms could indeed add to the nonlinear behavior of the circuitry (Awatramani and Slaughter, 2000), but the realistic shape of the obtained curves argues against a strong influence. For similar reasons we believe that the omission of nonlinearities at bipolar cell synapses is not critical for the conclusions of this study (see below).

The role of the different amacrine cells is currently probably the most confusing aspect of retinal function as many subtypes exist, some of which might contribute to ganglion cell nonlinearities. Little is known about their connectivity and function. Therefore, our model omits many of the existing subtypes (Strettoi and Masland, 1996; Kolb, 1997; Masland, 2001), and instead we have focused on two amacrine circuits for which more unambiguous 


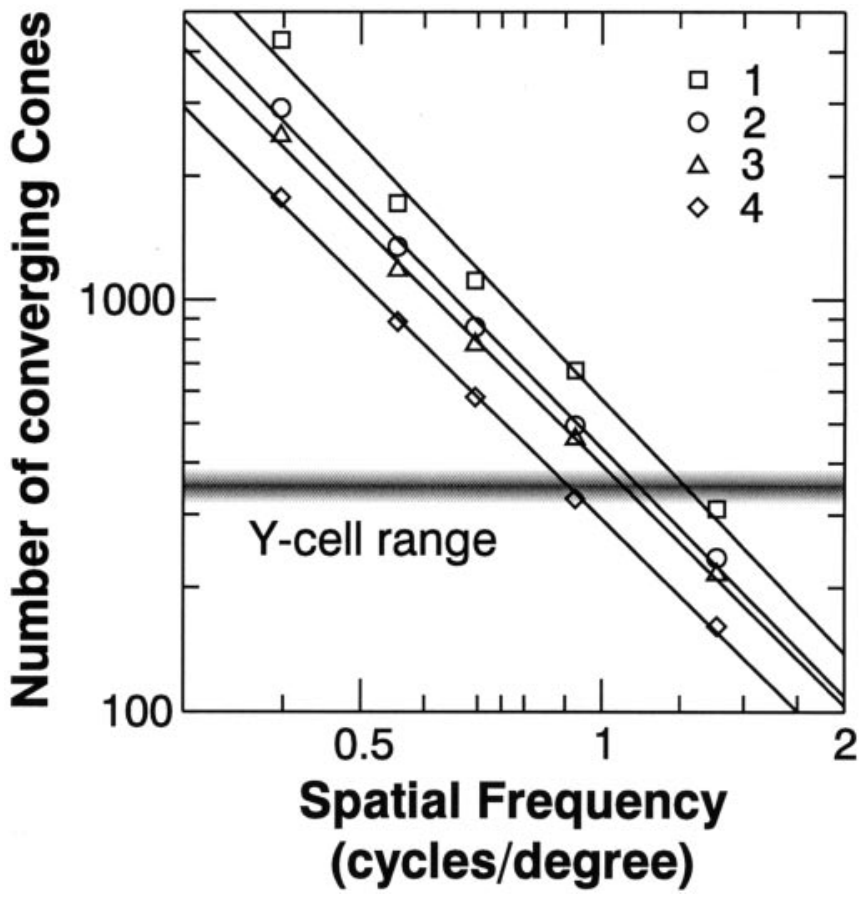

Figure 10. The cone convergence number in which the first and second harmonic response curves in Figure 9 intersect as a function of the spatial frequency of the stimulus. Stimuli were sinusoidally modulated sine wave gratings, and only receptive field sizes in the range of Y-cells (shaded region) and larger were considered, because realistic X-cells are largely linear. For the spatial frequency range from 0.4 to $1.4 \mathrm{cpd}$, the shapes of the first and second harmonic curves are similar to the curves in Figure 9, and it was possible to determine the point of intersection. At lower spatial frequencies, the location of the intersection was at convergence numbers that exceeded the size of the simulated cell grid. The curve labeled 1 belongs to the case in which the amacrine cells are inactive and the "linear" photoreceptor has been used. In curve 2, the nested amacrine circuit has been activated. Curve 3 represents the nonlinear photoreceptor without amacrine cells (X-like) and curve 4 the nonlinear receptor and active amacrine cells (Y-like). The shaded region indicates the convergence number for a Y-cell at $1^{\circ}$ eccentricity. The curves $1-4$ in this diagram can be fitted by linear functions $c_{\mathrm{i}}=m x+b_{\mathrm{i}}, i=1, \ldots 4$ (shown as lines) with a slope of $m=-1.97 \pm 0.06$ for all four curves and with $b_{1}=$ $6.349, b_{2}=6.073, b_{3}=5.981$, and $b_{4}=5.679$. A shift parallel to the $y$-axis in the double-logarithmic domain is equivalent to a multiplication in the linear domain, and the resulting relation $b_{4}=-b_{1}+b_{2}+b_{3}$ allows for the estimation $b_{4 \text {,est }}=5.705 \approx b_{4}$. This shows that a multiplicative relation provides a reasonable fit for the interaction of different sources of nonlinearities in the model retina.

data exist: type 1 amacrine cells (Flores-Herr et al., 2001) and the nested amacrine circuit (Roska et al., 1998; Passaglia et al., 2001).

$\mathrm{X}$ - and Y-ganglion cells have been treated as a uniform class with respect to their physiological properties. This rules out any internal property that promotes nonlinear responses in Y-cells (Robinson and Chalupa, 1997; Cohen, 1998). The synaptic transmission from bipolar to ganglion cells normally involves AMPAand NMDA-type receptors (Matsui et al., 1998; Cohen, 1998; Cohen, 2000), of which only the AMPA-type has been modeled. The NMDA receptor introduces a rectification for membrane potentials of less than $-40 \mathrm{mV}$, which could reduce the asymmetry and linearize the final responses of ganglion cells.

In an earlier version of this model two types of Off-center cells (brisk and sluggish; Cleland and Levick, 1974) had been included. It was not possible to model a brisk Off-center cell (depolarizing at contrast reversals) as a mirror image of an
On-center cell. We found that an additional rectifying nonlinearity was required at the photoreceptor to bipolar cell synapse, similar to the suggested nonlinearity at the bipolar to ganglion cell synapse by Demb et al. (2001). Such a nonlinearity is largely hypothetical, and a quantitative model analysis of brisk Offcenter cell responses is not yet possible. Sluggish Off-center cells, on the other hand, can be modeled as an exact mirror image of our simulated On-center cells so that the same conclusions are applicable to these cells.

\section{Nonlinearities in retinal neuronal responses}

Unavoidably, all neuronal responses, graded or spiking, are nonlinear. Even without additional influences, this is attributable to the fact that the reversal potential of ionic currents leads to boundary effects. As a consequence, the model cell spectra beyond the photoreceptors still contain higher harmonics even in the case of an inactive nested amacrine circuit and a linearized photoreceptor. Thus, synaptic transmission nonlinearities can be regarded as the first and pervasive source of nonlinear behavior in the retinal network.

In the realistically modeled photoreceptors, the mechanisms of phototransduction combined with membrane nonlinearities create the input nonlinearity of the system. The resulting nonlinear effects manifest themselves in the responses of the other cell classes, where the receptive field size determines the strength of the nonlinearity. For ganglion cells, this is illustrated in Figure 11.

Gaudiano (1992a,b, 1994) and Gaudiano et al. (1998) already suggested that receptive field size could play a role in the generation of retinal nonlinearities. Our results support this view, but the push-pull intraretinal connectivity he introduced does not seem to be necessary for nonlinear responses. Experimental evidence also shows that frequency doubled responses are generated in the same channel (On or Off) to which the ganglion cell also belongs (Demb et al., 1999), ruling out a push-pull connectivity as source of Y-cell nonlinearities. On the other hand, a balanced push-pull connectivity could indeed linearize the responses of X-cells, as has been suggested for the visual cortex (Pollen and Ronner, 1982; Ferster, 1988; Wörgötter et al., 1998).

The third source for nonlinearities arises from the intraretinal connectivity, most prominently through amacrine cells. The first experimental indications that amacrine cells in general have a weaker effect on retinal nonlinearities as compared with other sources came from the results of Demb et al. (2001) (see their Figs. 4 and 8). We confirmed their observations and the current model furthers their conclusions by showing that the nested amacrine circuit enhances the nonlinearity of Y-cells for high but reduces it for low spatial frequencies. However, other sources of nonlinearities might exist that have not been considered in our model.

One possible source could be depression at excitatory synapses (Thomson and Deuchars, 1994; Zucker and Regehr, 2002), which could lead to a harmonic distortion of the signal. The data of Demb et al. (1999, their Fig. 2) shows a distinctive difference in the behavior of the first and second harmonics of ganglion cell responses to drifting versus counterphasing gratings; only during contrast reversal does a strong second harmonic exist. This behavior could be reproduced with our model (data not shown), because for moving gratings the temporal properties of the amacrine circuit perfectly compensate the asymmetries in the photoreceptor responses. If a strong depressing synapse from the bipolar to the ganglion cell exists, we would expect a strong distortion of the signal in both cases. This suggests that synaptic 


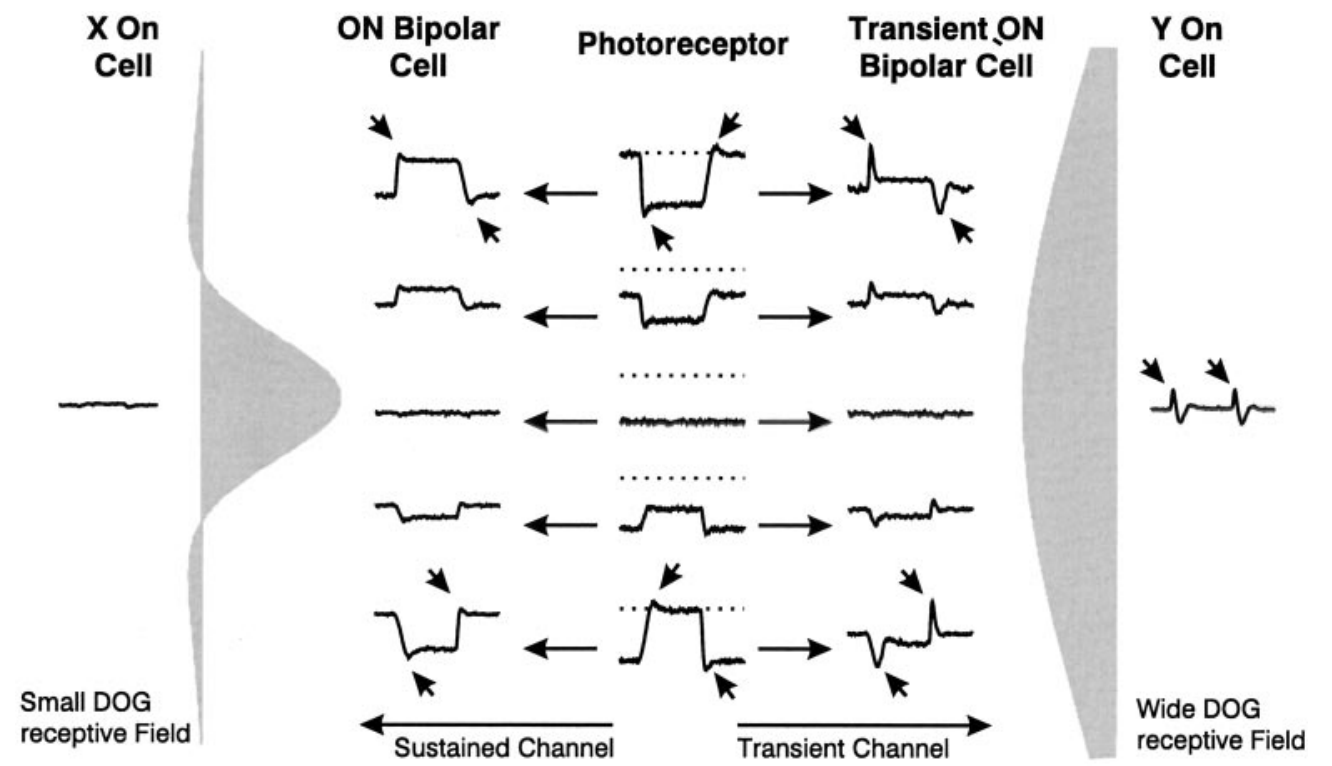

Figure 11. Schematic diagram illustrating the origin of null responses in X-cells (left $t$ and frequency-doubled responses in Y-cells (right). Traces are vertically aligned relative to a contrast reversed sinusoidal grating (middle trace represents the $0^{\circ}$ phase). The $\mathrm{X}$-cell receives most of its input from the central photoreceptor and faithfully reproduces the null response. For every given retinal eccentricity, Y-cells receive a higher number of photoreceptor inputs than X-cells, which is equivalent to a larger receptive field. Photoreceptor responses, however, are asymmetrical with respect to light onand offset (marked by arrows), and this asymmetry is enhanced further by the nested amacrine circuit that shapes the responses of the transient bipolar cell terminal. Summing these responses across the receptive field of a Y-cell results in depolarizations at each contrast reversal.

depression has only a weak effect on the nonlinearity of ganglion cells responses.

Another possible source of ganglion cell nonlinearities is from different types of bipolar cells, which selectively provide linear or nonlinear input to $\mathrm{X}$ - and Y-cells (Wu et al., 2000). In the cat retina, On-X-cells receive half of their excitatory input from transient b1 bipolar cells and the rest from the sustained types b2/b3 (Cohen and Sterling, 1992; Freed, 2000). On-Y-cells receive excitatory input almost entirely from the b1-type (Freed and Sterling, 1988). The source of the transient behavior of b1-bipolars is still unknown. Our model suggests that it could arise retrogradely through the properties of the nested amacrine circuit, which generates transient responses in bipolar cells (as shown in Fig. $1 B$ ). Thus, one could view the model bipolar cells which connect to Y-cells as the b1-type, whereas those that connect to $\mathrm{X}$-cell represent the group of b2,b3-bipolars.

\section{REFERENCES}

Awatramani GB, Slaughter MM (2000) Origin of transient and sustained responses in ganglion cells of the retina. J Neurosci 20:7087-7095.

Bader CR, Bertrand D (1984) Effect of changes in intra- and extracellular sodium on the inward (anomalous) rectification in salamander photoreceptors. J Physiol (Lond) 347:611-631.

Boycott BB, Wässle H (1974) The morphological types of ganglion cells of the domestic cat's retina. J Physiol (Lond) 240:397-419.

Cleland BG, Levick WR (1974) Brisk and sluggish concentrically organized ganglion cells in the cat's retina. J Physiol (Lond) 240:421-456.

Cohen E, Sterling P (1991) Microcircuitry related to the receptive field center of the On-Beta ganglion cell. J Neurophysiol 65:352-359.

Cohen E, Sterling P (1992) Parallel circuits from cones to the on-beta ganglion cell. Eur J Neurosci 4:506-520.

Cohen ED (1998) Interactions of inhibition and excitation in the lightevoked currents of $\mathrm{X}$ type retinal ganglion cells. J Neurophysiol 80:2975-2990.

Cohen ED (2000) Light-evoked excitatory synaptic currents of X-type retinal ganglion cells. J Neurophysiol 83:3217-3229.

Dacey D, Packer OS, Diller L, Brainard D, Peterson B, Lee BB (2000) Center surround receptive field structure of cone bipolar cells in primate retina. Vision Res 40:1801-1811.

Demb JB, Haarsma L, Freed MA, Sterling P (1999) Functional circuitry of the retinal ganglion cell's nonlinear receptive field. J Neurosci 19:9756-9767.

Demb JB, Zaghloul K, Haarsma L, Sterling P (2001) Bipolar cells contribute to nonlinear spatial summation in the brisk-transient (Y) ganglion cell in mammalian retina. J Neurosci 21:7447-7454.

Demontis GC, Longoni B, Barcaro U, Cervetto L (1999) Properties and functional roles of hyperpolarization-gated currents in guinea-pig retinal rods. J Physiol (Lond) 515:813-828.
Enroth-Cugell C, Robson JG (1966) The contrast sensitivity of retinal ganglion cells of the cat. J Physiol (Lond) 187:517-552.

Fain GL, Matthews HR, Cornwall MC, Koutalos Y (2001) Adaptation in vertebrate photoreceptors. Physiol Rev 81:117-151.

Feigenspan A, Wässle H, Bormann J (1993) Pharmacology of GABA receptor $\mathrm{Cl}$ channels in rat retinal bipolar cells. Nature 361:159-161.

Ferster D (1988) Spatially opponent excitation and inhibition in simple cells of the cat visual-cortex. J Neurosci 8:1172-1180.

Fisher J, Krüger J, Droll W (1975) Quantitative aspects of the shift effect in cat retinal ganglion cells. Brain Res 83:391-403.

Flores-Herr N, Protti DA, Wässle H (2001) Synaptic currents generating the inhibitory surround of ganglion cells in the mammalian retina. J Neurosci 21:4852-4863.

Freed MA (2000) Parallel cone bipolar pathways to a ganglion cell uses different rates and amplitudes of quantal excitation. J Neurosci 20:3956-3963.

Freed MA, Sterling P (1988) The ON-alpha ganglion cell of the cat retina and its presynaptic cell types. J Neurosci 8:2303-2320.

Freed MA, Pflug R, Kolb H, Nelson R (1996) ON-OFF amacrine cells in cat retina. J Comp Neurol 364:556-566.

Freeman AW (1991) Spatial characteristics of the contrast gain control in the cat's retina. Vision Res 31:775-785.

Frishman AW, Linsenmeier RA (1982) Effects of picrotoxin and strychnine on non-linear responses of Y-type cat retinal ganglion cells. J Physiol (Lond) 324:347-363.

Gaudiano P (1992a) A unified neural network model of spatiotemporal processing in $\mathrm{X}$ and $\mathrm{Y}$ retinal ganglion-cells. I. analytical results. Biol Cybern 67:11-21.

Gaudiano P (1992b) A unified neural network model of spatiotemporal processing in $\mathrm{X}$ and $\mathrm{Y}$ retinal ganglion-cells. II. temporal adaptation and simulation of experimental data. Biol Cybern 67:23-34.

Gaudiano P (1994) Simulations of $\mathrm{x}$ and y retinal ganglion cell behavior with a nonlinear push-pull model of spatiotemporal retinal processing. Vision Res 34:1767-1784.

Gaudiano P, Przybyszewski AW, van Wezel RJA, van de Grind WA (1998) Spatial asymmetries in cat retinal ganglion cell responses. Biol Cybern 79:151-159.

Hennig MH, Funke K (2001) A biophysically realistic simulation of the vertebrate retina. Neurocomputing 38:659-665.

Hennig MH, Wörgötter F, Funke K (2001) Nonlinear receptive field properties of retinal ganglion cells originate from inherent asymmetry of photoreceptor responses. In: Göttingen neurobiology report 2001, Vol 2 (Elsner N, Kreutzberg G, eds), p 547. New York: George Thieme Verlag

Hochstein S, Shapley RM (1976) Linear and nonlinear spatial subunits in Y cat retinal ganglion cells. J Physiol (Lond) 262:265-284.

Kaplan E, Benardete E (2001) The dynamics of primate retinal ganglion cells. Prog Brain Res 134:17-34.

Koch C (1999) Biophysics of computation: information processing in single neurons. Oxford: Oxford UP.

Kolb H (1997) Amacrine cells of the mammalian retina: neurocircuitry and functional roles. Eye 1:904-923.

Krüger J, Fischer B (1973) Strong periphery effect in cat retinal ganglion 
cells. Excitatory responses in $\mathrm{ON}$ - and OFF-center neurones to single grid displacements. Exp Brain Res 18:316-318.

Kuffler SW (1953) Discharge patterns and functional organization of mammalian retina. J Neurophysiol 16:37-68.

Laitko U, Hofmann KP (1998) A model for the recovery kinetics of rod phototransduction, based on deactivation on rhodopsin. Biophys $\mathrm{J}$ 74:803-815.

Lankheet MJ, Frens MA, van de Grind WA (1990) Spatial properties of horizontal cell responses in the cat retina. Vision Res 30:1257-1275.

Lankheet MJM, Prickaerts JHHJ, van de Grind WA (1992) Responses of cat horizontal cells to sinusoidal gratings. Vision Res 32:997-1008.

Lee BB, Kremers J, Yeh T (1998) Receptive fields of primate retinal ganglion cells studied with a novel technique. Vis Neurosci 15:161-175.

Lee BB, Dacey DM, Smith VC, Pokorny J (1999) Horizontal cells reveal cone type-specific adaptation in primate retina. Proc Natl Acad Sci USA 96:14611-14616.

Linsenmeier RA, Frishman LJ, Jakiela HG, Enroth-Cugell C (1982) Receptive-field properties of $\mathrm{X}$ and $\mathrm{Y}$ cells in the cat retina derived from contrast sensitivity measurements. Vision Res 22:1173-1183.

Marc RE, Liu WLS (2000) Fundamental GABAergic amacrine cell circuitries in the retina: Nested feedback, concatenated inhibition, and axosomatic synapses. J Comp Neurol 425:560-582.

Masland RH (2001) Neuronal diversity in the retina. Curr Opin Neurobiol 11:431-436.

Matsui K, Hosoi N, Tachibana M (1998) Excitatory synaptic transmission in the inner retina: paired recordings of bipolar cells and neurons of the ganglion cell layer. J Neurosci 18:4500-4510.

McIlwain JT (1964) Receptive fields of optic tract axons and lateral geniculate cells: peripheral extend and barbiturate sensitivity. J Neurophysiol 27:1154-1173.

McNaughton PA (1990) Light responses of vertebrate photoreceptors. Physiol Rev 70:847-883.

Müller F, Kaupp UB (1998) Signaltransduktion in Sehzellen. Naturwissenschaften 85:49-61.

Nelson R (1977) Cat cones have rod input: a comparison of the response properties of cones and horizontal cell bodies in the retina of the cat. J Comp Neurol 172:109-136.

Nirenberg S, Meister M (1997) The light response of retinal ganglion cells is truncated by a displaced amacrine circuit. Neuron 18:637-650.

Oshima S, Yagi T, Funahashi Y (1995) Computational studies on the interaction between red cone and $\mathrm{H} 1$ horizontal cell. Vision Res 35:149-160.

Passaglia CL, Enroth-Cugell C, Troy JB (2001) Effects of remote stimulation on the mean firing rate of cat retinal ganglion cells. J Neurosci 21:5794-5803.

Pollen DA, Ronner SF (1982) Spatial computation performed by simple and complex cells in the visual-cortex of the cat. Vision Res 22:101-118.

Robinson DW, Chalupa LM (1997) The intrinsic temporal properties of alpha and beta retinal ganglion cells are equivalent. Curr Biol 7:366-374.

Rodieck RW, Stone J (1965) Analysis of receptive fields of cat retinal ganglion cells. J Neurophysiol 28:833-849.

Roska B, Werblin F (2001) Vertical interactions across ten parallel, stacked representations in the mammalian retina. Nature 410:583-587.

Roska B, Nemeth E, Werblin FS (1998) Response to change is facilitated by a three-neuron disinhibitory pathway in the tiger salamander. J Neurosci 18:3451-3459.

Sato Y, Yamamoto M, Nakahama H (1976) Variability of interspike intervals of cat's on-center optic tract fibres activated by steady light spot: a comparative study on $\mathrm{X}$ - and Y-fibres. Exp Brain Res 24:285-298.
Satoh H, Kaneda M, Kaneko A (2001) Intracellular chloride concentration is higher in rod bipolar cells than in cone bipolar cells of the mouse retina. Neurosci Lett 310:161-164.

Schnapf JL, Nunn BJ, Meister M, Baylor DA (1990) Visual transduction in cones of the monkey Macaca fascicularis. J Physiol (Lond) 427:681-713.

Schneeweis DM, Schnapf JL (1999) The photovoltage of macaque cone photoreceptors: adaptation, noise and kinetics. J Neurosci 19:1203-1216.

Shapley RM, Victor JD (1978) The effect of contrast in the transfer properties of cat retinal ganglion cells. J Physiol (Lond) 285:275-298.

Smirnakis SM, Berry MJ, Warland DK, Bialek W, Meister M (1997) Adaptation of retinal processing to image contrast and spatial scale. Nature 386:69-73.

Smith RG, Sterling P (1990) Cone receptive field in cat retina computed from microcircuitry. Vis Neurosci 5:453-461.

Smith VC, Pokorny J, Lee BB, Dacey DM (2001) Primate horizontal cell dynamics: an analysis of sensitivity regulation in the outer retina. J Neurophysiol 85:545-558.

Steinberg RH, Reid M, Lacy PL (1973) The distribution of rods and cones in the retina of the cat (Felis domesticus). J Comp Neurol 148:229-248.

Strettoi E, Masland RH (1996) The number of unidentified amacrine cells in the mammalian retina. Proc Natl Acad Sci USA 93:14906-14911.

Thomson AM, Deuchars J (1994) Temporal and spatial properties of local circuits in neocortex. Trends Neurosci 17:119-126.

Troy JB, Robson JG (1992) Steady discharges of X and Y retinal ganglion cells of cat under photopic illumination. Vis Neurosci 9:535-553.

Troy JB, Oh JK, Enroth-Cugell C (1993) Effect of ambient illumination on the spatial properties of the center and surround of Y-cell receptive fields. Vis Neurosci 10:753-764.

Troy JB, Bohnsack DL, Diller LC (1999) Spatial properties of the cat $\mathrm{X}$-cell receptive field as a function of mean light level. Vis Neurosci 16:1089-1104.

Vakkur GJ, Bishop PO (1963) The schematic eye in the cat. Vision Res 3:357-381.

Vardi N, Zhang LL, Payne JA, Sterling P (2000) Evidence that different cation chloride cotransporters in retinal neurons allow opposite responses to GABA. J Neurosci 20:7657-7663.

Victor JD (1988) The dynamics of cat retinal Y cell subunit. J Physiol (Lond) 405:289-320.

Wässle H, Boycott BB (1991) Functional architecture of the mammalian retina. Physiol Rev 71:447-479.

Wässle H, Boycott BB, Peichl L (1978) Receptor contacts of horizontal cells in the retina of the domestic cat. Proc R Soc Lond B Biol Sci 203:247-267.

Wörgötter F, Koch C (1991) A detailed model of the primary visual pathway in the cat: comparison of afferent excitatory and intracortical inhibitory connection schemes for orientation selectivity. J Neurosci 11:1959-1978.

Wörgötter F, Nelle E, Li B, Wang L, Diao Y (1998) A possible basic cortical microcircuit called "cascaded inhibition". Exp Brain Res $122: 318-332$

Wu SM, Gao F, Maple BR (2000) Functional architecture of synapses in the inner retina: Segregation of visual signals by stratification of bipolar cell axon terminals. J Neurosci 20:4462-4470.

Yagi T, Ohshima S, Funahashi Y (1997) The role of retinal bipolar cell in early vision: an implication with analogue networks and regularization theory. Biol Cybern 77:163-171.

Zucker RS, Regehr WG (2002) Short-term synaptic plasticity. Annu Rev Physiol 64:355-405. 